\title{
ReVista Internacional de Sociología (RIS)
}

Vol.72, Nº 2, MAYo-Agosto, 287-302, 2014

ISSN: 0034-9712

eISSN: 1988-429X

DOI:10.3989/ris.2013.09.12

\section{SOCIODICEA}

\section{SOCIODICY}

SALVADOR GINER salvadorginer00@gmail.com

Institut d'Estudis Catalans. Barcelona. España.

\section{Resumen}

Este ensayo analiza la justificación social del mal y del daño, un fenómeno clave para la construcción moral de la realidad social. Inspirándose en la noción leibniziana de teodicea, de la cual es una versión secularizada, se exploran algunos ejemplos de explicación y justificación 'sociodiceica' de tales hechos. Se muestra la considerable importancia que estas concepciones poseen en el orden moral de las sociedades contemporáneas.

\section{Palabras Clave}

Desigualdad, Injusticia, Orden moral

\section{Abstract}

This essay analyzes the social justification of evil, a key phenomenon in the moral construction of social reality. Taking its cue from Leibniz's notion of theodicy, of which sociodicy is largely a secularized version, some examples of 'sociodicean' explanations and justifications are explored. The considerable importance of these conceptions in the moral order of contemporary societies is shown.

\section{KEYWORDS}

Inequality, Moral order, Unjustice. 


\section{$I^{*}$}

La atribución de un daño a una situación social dada es más enigmática de lo que se suele suponer. Lo mismo acaece con la justificación del mal por parte de quienes lo ejercen, aunque lo sea menos para quienes lo sufren. Atribución y justificación son el haz y el envés de la sociodicea. Mientras que toda teodicea presenta, de raíz, dificultades lógicas insolubles, la sociodicea, en cambio, escapa a algunos de los dilemas insuperables que caracterizan a la primera. La inteligencia mundana y sociológica del universo humano, por lo que respecta a la explicación racional y objetiva del mal socialmente engendrado, también encuentra escollos. Aunque son bastante menos intratables que los de la teodicea, dejan algunas cuestiones abiertas. Por ahora siguen sin encontrar una respuesta satisfactoria.

La teodicea es un proyecto imposible. Su propio triunfo entrañaba su fracaso ${ }^{1}$. Para quienes no comulgamos - literalmente — con los supuestos que obligan a planteársela posee solo el interés que genera la curiosidad intelectual. Así, no deja de llamar la atención que haya teólogos que se devanen los sesos habiéndoselas con el más insuperable de los dilemas y la más atroz de las aporías que haya inventado la imaginación humana. O Dios es todo bondad, y sin embargo permite el mal, o no lo es, y entonces no es Dios. Para quienes no deseemos enzarzarnos en tan espinoso y hasta bizantino asunto, resta siempre la cuestión lateral, y no menor, de saber por qué hay gentes que no sólo no se arredran ante aporías como éstas, sino que insisten en ponderarlas, estudiarlas y darles respuesta. La Teodicea de Leibniz no es una obra menor. Y el "necesitarianismo" de Spinoza, por su lado, podría conducir a conclusiones semejantes a partir de su naturalismo y su monismo. Aunque Leibniz tuviera que haber sufrido el oprobio para siempre por haber afirmado que éste es el mejor de los mundos posibles, y ser así presa facilísima del sarcasmo voltairiano, tal vez tuviera más razón de la que se le otorga. En el siglo XXI los físicos teóricos y otros sabios dedicados a la cosmología aún se plantean si éste no será el único universo posible, aunque la hipótesis contraria — la de la pluralidad de universos- les parezca no menos atractiva. Por lo general, todo sea dicho, no aseveran que sea el mejor posible, pero sí que, si no hubiera otro, estarían interpretando correctamente al gran matemático del XVII. A saber si quien lo interpretó mal fue, a pesar de todo, el conmovedor Doctor Pangloss.

\footnotetext{
${ }^{1 *}$ Agradecimientos: He incorporado a este ensayo la ayuda que me han proporcionado muy amablemente Fernando Aguiar, Hugo Pérez Hernáiz, Manuel Pérez Yruela, Pere Ramírez i Molas, José Enrique Rodríguez Ibáñez y David Tàbara. Un primer avance de este estudio, en forma harto esquemática, apareció en la revista Claves de Razón Práctica, en el número 227, marzo, 2013, pp.82-91.

Como ha observado Manlio Sgalambro en su Diario teologico: 'Il compito della teodicea fu assolto nello stesso momento in cui essa scomparse, non per averlo fallito ma perr essere riuscita in pieno. In ultima analisi essa fece sparire la nozione stessa di male." (1993). Cf. también Sgalambro (2004).
} 
Pensar es justificar. No sólo juzgar². En la contemplación de la sociedad humana entra el esfuerzo por explicar, justificando, las causas de lo que en ella acaece. Sobre todo cuando, como animales morales que somos, las condenamos. Explicamos desafueros y maldades alegando que su causante ha perdido el uso de razón, o que es un sádico cuya enfermedad le hace cometer perversidades. Naturalmente, pueden darse situaciones en que domine lo absurdo y sea menester sumirnos en la más absoluta perplejidad: el mundo se hace entonces inexplicable y se suspende toda nuestra capacidad de justificación. Aunque no puedan ignorarse -y menos en nuestro tiempo- situaciones dominadas por el reino de lo absurdo, constatemos que la inclinación predominante es la de dar (y darnos) cuenta y razón de por qué las cosas son, en cada caso, como son. Para muchos, la fe religiosa suministra respuestas satisfactorias que explican aquello que es inexplicable mediante el uso de la razón o la indagación. Tal fe no resiste el escrutinio analítico, lógico o racional más elemental. Ello no le resta interés -antropológico, étnico, psicológico- mas éste ya es otro asunto, ajeno al que mueve estas consideraciones.

Si a ese 'dar cuenta y razón' le agregamos una dimensión moral, decimos que no sólo explicamos, sino que justificamos. Es decir, que introducimos un elemento moral. Ese elemento no está ausente aunque atribuyamos males y daños a fuerzas impersonales. Así, el lenguaje corriente atribuye a menudo los males a un orden perverso del mundo social: el 'capitalismo', las 'finanzas', el 'partido político único', el 'fanatismo supersticioso de una religión' u otras entidades que fomentan toda suerte de codicias, insidias, deshonestidades, desafueros y crueldades. Tradicionalmente, solía atribuirse el mal a pueblos enteros, definidos como enemigos - tribus o naciones extranjeras, amenazas frecuentemente reales, con frecuencia invasoras de nuestro territorio o nuestras vidas y haciendas - y hasta a colectividades inocentes - como la hebrea, expulsada de Inglaterra en 1290 o, más tarde, de España, en 1492, como si tuvieran la 'culpa' de sus males, 0 aniquiladas ya en nuestro tiempo por Alemania, presa de la demencia nazi- como si existieran culpas impersonales y colectivas. 0 , por desplazamiento del odio, cuando no es posible vencer a los auténticos responsables de los daños.

Aunque el origen de tales comportamientos dañinos se atribuya a causas impersonales -el partido totalitario, la fe irracional en fuerzas sobrenaturales, la existencia del mal o del pecado compartido por razas, linajes, naciones o comunidades de creyentes- las gentes suelen culpar a personas. Así, decimos que desencadena una guerra porque el agresor es un tirano fanático, una crisis económica porque hay desalmados financieros que así lo han deseado, o para ello conspirado ${ }^{3}$; me abandona mi novia porque ha encontrado un mejor partido que yo, aunque sea menos apuesto, inteligente y simpático;

${ }^{2}$ Denken ist Urteilen, según la lapidaria expresión kantiana, en los Prolegomena. (Cf. Eisler, 1989).

${ }^{3} \mathrm{Cf}$. Hugo A. Pérez Hernáiz (2011). El autor se inclina por la expresión "teodicea secularizada" noción que posee afinidades notables con la mía de sociodicea. 
fulano ha ganado una oposición a funcionario porque tenía padrinos, o supo sobornar a los jueces; los aristócratas y la nobleza dominan aquel país remoto porque son más ricos, pero también más maliciosos al aferrarse a sus prebendas, o más capaces e inteligentes para dominar, diría memorablemente un sociólogo clásico ${ }^{4}$; los traficantes de armas prefieren sus beneficios a las vidas humanas que su nefasto negocio produce; a un partido político le importa más acopiar votos que sus principios proclamados, más aún, que salvar el medio ambiente o dar asistencia médica a los necesitados. (Ni el uno ni los otros, votan.) Y así ad infinitum.

A este fenómeno llamamos sociodicea. La justificación social del mal es la sociodicea. Posee un doble sentido. En el más amplio de los posibles, la sociodicea es también la justificación de la sociedad tal cual, es decir, la aceptación de que el mundo es así, y que éste es su orden natural y posible: 'siempre habrá pobres', 'siempre habrá hampa', 'siempre, sinvergüenzas', 'siempre, desigualdad injusta'.. Esta versión no excluye el reformismo ni es necesariamente cínica, ni fatalista, pero plantea cuestiones ciertamente vastas sobre el orden general de la sociedad y su posible mejora que aquí soslayaré con cautela. En su segunda acepción, la más circunscrita, la sociodicea es la justificación de un mal determinado, que se juzga necesario.

Las dos visiones de la sociodicea -la más inclusiva, que incorpora la sociedad entera con sus imperfecciones y calamidades, y la más restringida, que acepta la existencia de ciertos males circunscritos, posiblemente subsanables, o extirpables- son muy distintas y entrañan filosofías morales, a la postre, incompatibles entre sí.

La sociodicea es la versión mundana de la teodicea. Parte, sin embargo, de supuestos radicalmente distintos y opuestos a los de la teodicea. El abismo entre ambas se me antoja insalvable. La teodicea es aquella parte de la teología dedicada a la explicación, presuntamente racional, del mal. Su objeto es, ante todo, explicar satisfactoriamente, con buenas razones, un universo moral contradictorio creado por Dios, en el que reina en calidad de Todopoderoso. Lo crucial en toda teodicea es explicar la presencia de los daños causados a seres humanos inocentes por otros seres humanos, amén de las desgracias naturales - la enfermedad, las catástrofes, el hambre - en un Universo en el que nada acaece sin voluntad ni permiso divino. La perversidad de los humanos que dañan, torturan, matan o simplemente amargan innecesariamente la vida de sus congéneres, debe ser explicada por la teodicea. ¿Por qué permite Dios su maldad?

Las muy humildes ciencias sociales están libres de esta elucubración. Circunscriben sus pesquisas a la naturaleza de la especie humana y a sus condiciones de existencia. Al hacer tal, incluyen en su programa la indagación de la causación social del mal y hasta, si cabe, de su justificación. Para esto último, para su justificación, hablamos de sociodicea, palabra híbrida grecolatina en que la justicia o diké se une a la alusión a nuestra especie. En esta tarea, por lo pronto, la ciencia social debe excluir de su indagación a las catástrofes naturales, las enfermedades y las fatalidades del vivir, morir,

\footnotetext{
${ }^{4}$ Sobre Vilfredo Pareto véase Giner (2004: 195-224).
} 
ante todo (aunque no así de su estudio de las respuestas humanas a tales calamidades, entre las que debe incluirse, como hace cierta escuela —llamada constructivista - el modo en que los hombres definen, interpretan e incluso inventan catástrofes naturales). En puridad el tsunami indonesio que causó tantos muertos en la Navidad de 2004; el que, desencadenado por un terremoto, asoló la costa japonesa en 2011; o, poco antes, el terremoto que devastó Haití en 2010, no forman parte de la problemática de la sociodicea, salvo en la imaginación teológica o escatológica de aquellas mentes mágicas que aún atribuyen a la ira de Dios o de los dioses, venganzas y castigos por nuestros presuntos pecados. Lo son, eso sí, las respuestas que los hombres les dieron o damos, como lo es el estudio de las causas humanas que engendran nuestra incapacidad por no tomar las medidas preventivas contra el daño previsible. Por ello sí lo son, en toda su extensión, las causas antrópicas de la destrucción ambiental en curso, las de la explosión demográfica que no controlamos, o las de la generación y promoción de una desigualdad social innecesaria o injusta ${ }^{5}$.

\section{II}

La noción de sociodicea es tan crucial como carente de historia independiente. Como quiera que, normalmente, las sociodiceas aparezcan como parte de la ideología, la tendencia ha sido a no identificarlas como tales. Las ideologías suelen incluir sus sociodiceas correspondientes, puesto que condenan, aprueban, explican y, sobre todo, justifican males o remedios para esos males. La parte justificativa y explicativa del mal es la sociodicea ideológica. La sociodicea, como parte de toda ideología, identifica culpables 0 atribuye causas a males y daños socialmente causados, al tiempo que abona y avala determinado estado de cosas. El rebus sic stantibus entraña en la sociodicea una vindicatio rerum.

La malicia de aquellos financieros que provocan adrede una recesión económica - a un extremo - o la estupidez humana, o la mera ignorancia, que genera daños y perjuicios no intencionales - al otro-, son dos ejemplos de explicaciones sociodiceicas. Otras, como el argumento (propio de cierto darwinismo social popular, común entre clases dominantes) de que el mundo pertenece a los más listos y poderosos, y debe ser natural e inevitablemente de quienes sepan adquirir y mantener su dominio son también, con un leve grado añadido de refinamiento teórico, razones sociodiceicas. Una tercera categoría explicativa es la mágica o teológica. La sociodicea sería para ello un apéndice de la teodicea. Dios, infinitamente bueno, ha creado seres malignos, o por lo menos capaces de maldad, en uso de la libertad que su creador les ha otorgado. Esta

${ }^{5} \mathrm{Cf}$. E. Garzón Valdés (2004), en donde las catástrofes se circunscriben a las provocadas por acciones humanas intencionales, así como H. Martins (2011). 
hipótesis no se considera, recién dicho está, en mi análisis, aunque sea muy interesante: pertenece a la sociología de lo sobrenatural, un aspecto de la de la religión. Y como tal, forma parte de la sociología de la religión y de las creencias en lo sobrenatural.

La palabra sociodicea es prácticamente un neologismo. El sociólogo Daniel Bell hizo uso de ella en el título de un ensayo de $1966^{6}$ sin desarrollar mínimamente el concepto. Sus sugerentes referencias allí a la 'alienación', a la 'ideología' y a la 'conspiración' de las clases dominantes contra el resto de los humanos y hasta contra el uso y abuso de expresiones vacuas como 'lo existencial' culminan con su sarcástica y admirable alusión a la 'sociologomaquia' que estropea lo que podría haber sido un buen debate teórico. Hay que agradecérselo, pero se hace difícil sostener que Bell produjera el ensayo seminal sobre la sociodicea que parecía haber anunciado su título. En todo caso, el esfuerzo inicial de Daniel Bell no encontró la herencia robusta que merecía. El concepto aparece en escasísimas ocasiones, y aun así sin encontrar, como fue el caso de Pierre Bourdieu, mayor explicación que unas alusiones pasajeras. Algunas de ellas, son notables. Entre ellas descuella la noción de que es el orden social mismo (y se entiende, no la clase dominante) el que produce la sociodicea ${ }^{7}$. En algún lugar, Bourdieu hasta la define lapidariamente: 'sociodicée, justification de la société.' (Bourdieu 1989: 103). Se entiende así que una sociodicea justifica un orden social tanto por parte de quienes se benefician directamente de ella como por parte de quienes la sostienen tras haber sido inculcados en sus creencias. Más específicamente, la sociodicea justifica ciertos males y daños ${ }^{8}$ causados por estructuras de dominación y pautas de poder, privilegio y clase. Lo cual indica que la diferencia entre ideología (dominante) y sociodicea propiamente dicha llega a ser a veces, bastante raquítica. Por lo menos en este autor. Pero no por ello son lo mismo. Como acabo de señalar, la sociodicea es un elemento de la ideología.

La sociodicea posee una historia potente en un sentido subterráneo o muy lato, como explicación de una sociedad humana imperfecta e injusta y como justificación de un orden social que contiene y genera ciertos males y daños. En numerosos casos, éstos se consideran superables a veces de uno u otro modo. Pero se suelen también juzgar como endémicos, o inevitables. (Ello emparenta a numerosas sociodiceas con el fatalismo; pero no todas adolecen de esta actitud ante el mundo). Desde el desencantamiento mágico a la expiación ante la Divinidad o la petición de misericordia a los Cielos,

\footnotetext{
${ }^{6}$ En Bell (1966), maravillosamente sarcástico, ataca diversas concepciones erróneas de diversos males ("alienación", "ideología", "fenomenología", "keynesianismo") sin detenerse suficientemente en lo que entiende por "sociodicea".

${ }^{7}$ En Méditations pascaliennes (2003: 87) P. Bourdieu habla de sociodicée epistemocratique (para la adquisición de conocimientos necesarios para obedecer un orden social), y en otros lugares de la sociodicea (burguesa) dominante e inculcada, y también de que es el orden social mismo el que produce su propia sociodicea. No desarrolla la noción.

${ }^{8}$ Vale la pena notar que las Méditations pascaliennes son un texto (último) de Bourdieu que no parece haber influido en los por un tiempo numerosos discípulos de este autor.
} 
hasta la exigencia de medidas humanas seculares y racionales para poner fin a los males que se identifican, abundan las soluciones que se suelen o se han solido poner en práctica. (La ineficacia manifiesta de algunas de las soluciones propuestas para acabar con tales males y daños rara vez ha persuadido a una parte muy considerable de la humanidad de que deban dejar de perseguirse).

Contra una extendida opinión, las sociodiceas no pueden reducirse a ser meras concocciones malignas de las clases dominantes o de fuerzas sociales hegemónicas, a formar parte solamente de sus ideologías. Así, desde la República platónica al Capital de Marx, son varias las sociodiceas a nuestro alcance que traspasan el angosto desfiladero ideológico. Alguna, como El espíritu de las leyes pueden —osaría decir, deben- leerse como capaces de tal amplitud de miras. Posiblemente, la de Montesquieu sea la más cumplida de las que poseamos. Por consiguiente, sería equivocado pensar que en esto el hábito hace al monje. La palabra no se usa en El Espíritu, pero la concepción que entraña, sí existe allí. Por confusa o nebulosa que sea para algunos. En efecto, si hay una cosmovisión, hay también una sociovisión explícita en Montesquieu, relativamente completa, y dotada de una argumentación coherente sobre lo justo y lo injusto dentro de ella (en torno a aquello que justifica la sociedad, tal cual es, para atenernos al significado estricto de la palabra sociodicea). Este último rasgo, la justificación de lo injusto, es el más definitorio de lo que el concepto híbrido, grecolatino, de sociodicea entraña ${ }^{9}$.

Si nos atenemos, como es aconsejable, al sentido estricto de lo que significa una sociodicea, la obra de Marx y Engels, sin ir más lejos, constituye también una sociodicea. La demolición de la sociedad burguesa y capitalista tanto vaticinada como propuesta por ambos sabios no justifica directa y moralmente tal orden social, pero sí lo hace con claridad meridiana en términos sociodiceicos, como estadio necesario (mal necesario, inevitable) en la evolución de la humanidad en su triunfal y trágica senda hacia el socialismo y, como culminación, hacia el comunismo del porvenir. (Los marxistas -y en general la izquierda - identifican causas objetivas y subjetivas —culpables, responsables - del daño, o hasta del mal.) Hay, por lo tanto y por lo menos, dos modos distintos de justificar la sociedad: llamémoslos la del Criterio de Pareto y la del Criterio de Marx. La primera, condena lo que hay, pero se resigna; la segunda, condena y no lo hace, aunque nunca oculta sus méritos y ventajas, como saben muy bien quienes de Marx no conocen más que una lectura apresurada del Manifiesto. Por su parte la 'resignación' paretiana —que es menos fatalista de lo que se imagina si recordamos su inclinación hacia la recomendación de mejorar las cosas según criterios de liberalismo

\footnotetext{
${ }^{9}$ Mientras que theo y diké (justicia) no confunden dos lenguas, la palabra sociodicea, sí lo hace. El precendente más conocido, y frecuentemente acusado de su incoherencia, es el de la palabra sociología. "La expresión "sociodicea" adolece de igual defecto. Si la palabra koinonía es la más cercana a "sociedad" en griego clásico -otras, como synodos, no cumplen del todo con el sentido general de "sociedad"- la resultante coherente se me antoja innecesariamente rebuscada.
} 
económico- proviene de una concepción muy explícita de la naturaleza humana, cuyos elementos invariantes, no pocos de ellos perniciosos, señaló con tanta vehemencia ${ }^{10}$.

Naturalmente, hay otras posibilidades, las más de las veces, intermedias, como aparecen por ejemplo en la majestuosa obra de Talcott Parsons - iquién lee hoy a Parsons ? $^{11}$ - cuya sociodicea evolutiva con creciente frecuencia soslaya la responsabilidad humana, y por lo tanto el problema sociológico del mal' ${ }^{12}$.

Precisamente Parsons, durante un período considerable, fue castigado inmisericordemente por una sociología autodefinida como radical (o progresista) como si su obra hubiera constituido una especie de justificación (conservadora) del mundo existente, o sociodicea. La cosa se degradó hasta el punto de que la acusación de ser "funcionalista" —epíteto bastante carente de sentido ideológico, entonces y ahora - se alzó contra quien era uno de los mayores científicos sociales del siglo XX. A menudo esa crítica, no carente de irritación, provenía de pensadores favorables a otros funcionalismos altamente sospechosos, de signo contrario ${ }^{13}$. Tengo para mí que el logro obtenido por parte de la entonces llamada ciencia social radical ${ }^{14}$ consistió más en desprestigiar el status científico de las ciencias sociales que en invalidar aquello que atacaba. Parsons, a su entender, había cometido el pecado mortal de justificar el mal, es decir, en mi propio lenguaje, producir sociodicea. No diría yo que se trataba de un pecado o perversidad interpretativa, sino de su habilidad para constatar lo obvio. Así, en un ensayo de 1940, raramente visitado por los aguerridos antiparsonianos de los decenios de 1960 a 1980, en torno a "Igualdad y desigualdad en la sociedad moderna" decía claramente Parsons:

"Las desigualdades entre las unidades de la estructura social que son esenciales en terrenos como son la productividad económica, la autoridad, el poder y la competencia basada en la cultura, deben justificarse en términos de su aportación al funcionamiento societario" (Parsons 1940)

No dice que sean buenas, ni que él personalmente las justifique, sino que socialmente —sobre todo, añado, en una politeya democrática — "deben justificarse" —que

\footnotetext{
${ }^{10}$ Me refiero a sus célebres "residuos", "derivaciones", "acciones lógicas" y "acciones no lógicas" que tanto han sufrido posteriormente del peculiar vocabulario empleado por él, pero que merecen la atención debida. Véase Giner (2004: 205-214).

11 ¿ ¿Who now reads Spencer?' Célebres primeras palabras de la gran obra de Talcott Parsons (1949: 3).

${ }^{12}$ No sólo los parsonianos, sino la inmensa mayoría de los científicos sociales (economistas, polítólogos y otros) descartan el mal y la culpa de sus consideraciones. Cf. Giner (2012) para este asunto (Nota 16).

${ }^{13}$ En ese sentido Alvin Gouldner hizo bien en incluir en sus ataques a la sociología convencional al marxismo, en su vigorosos escritos The Coming Crisis of Western Sociology (1971) y For Sociology (1973).

${ }^{14}$ No me refiero sólo a la llamada "radical sociology" propia de cierta época, puesto que a su lado surgió, sobre todo en los decenios de los años 60 y 70 del siglo pasado, una "economía radical" y una antropología no menos "radical", con extensiones a la ciencia política. Cf. J.E. Rodríguez Ibáñez (1978) y F. Ferrarotti (1972) Una sociologia alternativa, con el significativo subtítulo Dalla sociologia come tecnica del confromismo alla sociologia critica.
} 
es lo que precisamente hace la sociodicea, justificar la injusticia. ¿O es que Parsons o quienes como él pensaban justificaban moralmente el parasitismo, la prevaricación, la riqueza desmesurada y libre de impuestos?

Naturalmente, toda la tradición que desde la ciencia social intente la demolición o por lo menos el socavamiento de esa injusticia, está libre de sociodicea, en su sentido de justificación de un mal necesario. Va, abiertamente, contra ella. La poderosa obra de Amartya Sen y su escuela está orientada desde el principio a la eliminación de los males e injusticias remediables, evitando toda utopía, sin intentar la creación "de un mundo perfectamente justo" (Sen, 2009: vii). Por fortuna, otras aportaciones, no necesariamente insertas en la interpretación de Sen, no cesan de enriquecer con nuevos datos y argumentos (Wilkinson y Picket 2009) el combate contra la inclinación sociodiceica de los sectores que se benefician del orden social realmente existente, si se me permite parodiar una feliz expresión con la que no ha mucho se referían algunos al socialismo totalitario. La sociodicea es con demasiada frecuencia el pretexto más mezquino para el fatalismo.

Estas corrientes libres de sociodicea se insertan en una tradición de la ciencia social como saber esencialmente moral, en el que el servicio a la verdad (objetiva, empírica y racionalmente obtenida) y los principios éticos de la fraternidad y la compasión no son mutuamente excluyentes (Giner 2012). Más bien al contrario, se necesitan entre sí.

III

La sociodicea, afín y con frecuencia coincidente con el pensamiento conservador, es a menudo, muy explícita. Ello no significa que no ocupe también un lugar privilegiado en el pensamiento radical revolucionario: éste pivota sobre una concepción de la insurrección o la rebelión, o hasta de la disidencia pacífica extrema, que no acepta los 'males de la sociedad' pero sí los daños y sacrificios que causará su alzamiento contra la situación juzgada intolerable. Se consideran menores a los males que se están sufriendo.

El síndrome sociodiceico es frecuente en los centros de poder y autoridad. Valgan dos ejemplos. El gobierno de los Estados Unidos, incapaz, como es natural, de verse a sí mismo o a las instituciones económicas del país como origen de ciertos males (origen que a otros se antoja obvio), ha estado singularmente falto de preparación para entender las razones que asistían a aquellos que emprendieron -y aún emprenden- la siniestra senda del terrorismo contra ese país o sus instituciones. Que al gobierno de los Estados Unidos el terror antiamericano les parezca injustificable (es decir, fuera de toda sociodicea) es más que comprensible. Con esa convicción intentó el gobierno desencadenar una guerra antiterrorista (war on terror) cuyo desenlace final aún no se conoce del todo ${ }^{15}$.

\footnotetext{
${ }^{15}$ Un tercer ejemplo, que he explorado en otro lugar, es el de la crisis ambiental contemporánea. Cf. S. Giner y D. Tábara (1988).
} 
A quienes juzgamos que el terrorismo siempre carece de justificación moral, también nos lo parece. Pero no coincide con la sociodicea (que se confunde en el caso de los islamistas violentos antiamericanos, abiertamente, con una teodicea) a la que rinden culto los fanáticos y quienes los manipulan.

No obstante la justa indignación moral y la congoja de la ciudadanía yanqui, empero, contrasta con su ceguera ante los otros males causados por la función imperial o hegemónica de ese país más allá de sus fronteras que, en cambio, es entendida comprensiblemente como mal por las víctimas inocentes de sus disfunciones. Además, lo que parece irrisorio a un ciudadano americano —o a muchos amigos de los Estados Unidos-, como la aseveración de que ese país es 'el gran Satán' de nuestro tiempo, como afirmaba un sangriento tirano en Oriente Medio, pertenece rigurosamente a una sociodicea, la que justifica el mal supuestamente necesario, es decir el terrorismo. Lo cual, por otra parte, no significa que una potencia amenazada, dotada de una constitución y gobierno democráticos, no caiga también en la tentación de ejercerlo como represalia o defensa. Nada la exonera: hay conductas que no pueden permitirse las politeyas democráticas. Como sabemos desde Tucídides: es una de sus servidumbres ${ }^{16}$.Una lógica diabólica semejante ha sido usada con consecuencias nefastas no sólo en crímenes terroristas como los acaecidos en las Torres Gemelas o en la Estación de Atocha, sino en la sociodicea propia de las llamadas 'organizaciones armadas' de algunos movimientos terroristas europeos. Por no aducir otros ejemplos, que hoy mismo, en África o el Oriente Medio responden a la lógica del terror contra inocentes.

Un segundo ejemplo, entre los muchos disponibles, es el del Vaticano. Su sociodicea es aún más selectiva que la de numerosos gobiernos. Como entidad esencialmente moral y moralizante, la Iglesia Católica identifica con meridiana claridad el origen de un número de males, que constituyen su propia sociodicea, como digo, enraizada en su caso en una teodicea. Desde la atribución de la condición pecaminosa a los seres humanos, según la esencial doctrina cristiana del pecado original, hasta la presencia activa de Satanás en el mundo (algo desacreditado en nuestros seculares días, pero ciertamente no abolida aún por la doctrina) la Iglesia, junto a un número significativo de sectas e iglesias cristianas o de otras religiones, atribuye el mal a una condición metafísica de los seres humanos. La ontología cristiana sitúa el mal en el Pecado Original, como parte de nuestra naturaleza, y no sólo en la sociedad como tal. La separación entre lo subjetivo y lo social es tan extrema que permite la redención -la cura del mal y de la culpa- de cada cual cuando no es posible la redención a través de una transformación de la sociedad. Lo que llama la atención desde la estricta perspectiva que aquí nos ocupa no es, sin embargo, este fenómeno, sino el hecho de que la sociodicea explícita por parte de la Iglesia consista en una explicación de los males de la sociedad como parte del panorama. Es evidente que, a partir del II Concilio Vaticano, de 1962, la Iglesia emprendió

\footnotetext{
${ }^{16}$ En La Guerra del Peloponeso, estos dilemas encuentran su locus classicus, en el dilema de que Atenas se sienta obligada a atacar otra ciudad democrática, a la que además unía un pacto de no agresión.
} 
una senda mucho más activa en la denuncia de males —la esclavitud, la subordinación de las mujeres, la intolerancia religiosa, la tolerancia de las tiranías- que no habían sido precisamente rasgos de su ideología hasta aquél momento. La tardanza de esa nueva actitud, cuando para algunos ya era demasiado tarde, dados los inmensos avances de la secularización moderna, podría atribuirse a una redefinición a la defensiva de su sociodicea, por no decir, su teodicea, puesto que ésta continúa y continuará estancada en el limbo de las aporías que señalé al principio.

\section{IV}

Sólo los utopistas sostienen a pies juntillas la posible erradicación completa del mal. A algunos de ellos les ha tocado poner en práctica la más cruel paradoja de todas las conocidas: la producción masiva del mal por parte de sus presuntos extirpadores. No es preciso en este lugar repetir argumentos que, desde Isaiah Berlin a Hannah Arendt, han resultado muy convincentes sobre este fascinante fenómeno, cuyos orígenes históricos en la República inglesa puritana de Oliver Cromwell y en la versión jacobina de la República francesa en Maximilien Robespierre son harto conocidos, y cuyo final cumplimiento en el estalinismo soviético o los diversos fascismos no lo son menos. Es interesante subrayar, sin embargo, que las sociodiceas de los totalitarismos poseen la doble característica de identificar la maldad con meridiana claridad, la senda infalible para abolirla o extirparla y, encima, justificar ambas cosas. Para los puritanos ingleses la mezcla de la monarquía absoluta, el 'papismo' de los católicos y no pocos anglicanos, y las fuerzas sobrenaturales del mal, constituían parte de una sociodicea que les permitió el uso sistemático del terror gubernamental y, en el caso de Irlanda, la práctica del genocidio. En el de los soviéticos, desde las purgas políticas estalinistas hasta la construcción de estados policía en la Europa de su imperio - 1945-1989_ abunda la información sobre la naturaleza de su sociodicea. No deja de llamar la atención que los pocos observadores occidentales que se han referido explícitamente a la imaginación, ideología y argumentación sociodiceica se hayan limitado a atribuírsela —con todas la razón, sin duda - a clases dominantes en el marco de la democracia liberal, burguesías las más de las veces, con olvido de esos otros casos, tan llamativos.

Claramente, esta problemática no es trivial, ni tampoco se limita a poseer cierto interés histórico, por no decir arqueológico. Pero sí es cierto que las nuevas condiciones del mundo en el siglo XXI, en un estado de intensísima e impredecible mudanza motivada por el alud tecnológico, la renovación robusta del capitalismo — con su capacidad para provocar y absorber constantemente innovación (Giner 2011) - requiere una revisión del anticuado lenguaje sobre las clases subordinadas y las dominantes. Esta es una afirmación más delicada de lo que parece, porque suele ser esgrimida con sospechoso entusiasmo por la derecha más rancia y aún por muchos neoliberales que, naturalmente, son incapaces de poner en práctica lo que tan vehemente proponen. Pocos espectácu- 
los son más peregrinos que el de los sermones neoliberales acusando a la 'izquierda' 0 al 'socialismo' (sic) de anticuados en sus doctrinas y vocabulario, cuando su propia doctrina liberal, mucho más vetusta y venerable que la contraria, no dice nada nuevo que no se dijera antes de John Stuart Mill, cuyo sensato reformismo asumo que a muchos de ellos horroriza.

La sociodicea neoliberal (a menudo coincidente con la propia de la ideología de las grandes empresas tecnológicas transnacionales, entregadas al fomento de la modernidad según su propia doctrina) se ha enriquecido con una intensa privatización de la solidaridad y hasta de los esfuerzos hacia la igualdad (siempre dentro de un orden) mediante el ocasional estímulo del altruismo cívico, tanto a nivel nacional como internacional. La sustitución parcial y a veces intensa de las responsabilidades del 'Estado de bienestar' por la iniciativa privada — con frecuencia con ánimo de lucro— ha significado que la sociodicea -la justificación del mal y la legitimación de sus remedios- ha sido privatizada también en buena medida. La mudanza ha sido menos dramática en países protestantes con mayor tradición que los católicos en este terreno, puesto que en estos últimos la práctica institucional de la caridad a menudo exoneraba a la ciudadanía de mayores virtudes que la del ejercicio en pleno albedrío de algunas 'buenas obras' ocasionales. También en este terreno las cosas han cambiado, y ya no es posible presentar una dicotomía muy diáfana. Uno u otro modo de habérselas con los males del mundo.

El establecimiento de 'redes sociales' y otras formas de crear comunidad cuando avanza la erosión del comunitarismo local es, en términos de sociodicea, claramente ambivalente. Hay redes sociales que forman comunidades, más o menos efímeras, más o menos difusas, de gentes afines, preocupadas por sí mismas, algunas de ellas tan vastas que rompen con los requisitos sociológicos de toda comunidad estricta. (Los estudiosos del asunto coinciden todos en formular la pregunta ¿Cuántos 'amigos' puede tener uno en el ciberespacio? ¿Cien? ¿Quinientos? ¿Cinco mil?) ¿Cuáles poseen una verdadera sociodicea y cuáles no? No huelga esta pregunta, puesto que una consideración del contenido de las redes produce un mapa moral considerable: hay conductas que se celebran o aprueban, otras que se condenan. Pululan los 'enemigos' en la red, males que acechan a sus usuarios -algunos de ellos perseguidos por la ley, y hasta por Interpol- pero también bienes o hasta dicha que alcanzar. El mal de la sociodicea internética será para unos el uso publicitario y empresarial de la red, que puede ser parasitada u ocupada para la compraventa o la promoción de productos comerciales. Para otros, y no sólo en la China, lo será la injerencia y el intervencionismo estatal o de un partido político. $\mathrm{O}$ la revelación masiva de secretos diplomáticos 0 estatales a través de redes internéticas ${ }^{17}$.

${ }^{17} \mathrm{Cf}$. E. Shils The Torment of Secrecy (1956) y el precedente locus classicus de Georg Simmel sobre 'El secreto y la sociedad secreta' como exploraciones primerizas del fenómeno. 
La sociodicea ultramoderna, hoy, fluye más que nunca. Ciertamente, el animal tradicionalista que suele ser el hombre, abraza nuevas herramientas para hacer triunfar sus propios prejuicios y creencias, antiguos o hasta ancestrales. Los levantamientos árabes de 2012, como otrora otras revoluciones —desde el siglo XIX, y no necesariamente desde la desencadenada contra el Sha de Persia y el establecimiento del hoy ya anquilosado régimen de los ayatolás - son casos en los que las exigencias de democratización radical se enraizaban en legitimaciones providencialistas, metafísicas y sobrenaturales, alcoránicas, y por lo tanto, por definición, en teodiceas y sociodiceas venerables. No obstante en algunas revoluciones en los albores del siglo XX, como la bolchevique o la de los Jóvenes Turcos contra el imperio Otomano que llevó a Mustafá Kemal al poder, se dan casos de formulaciones muy seculares y por lo tanto radicalmente nuevas del mal a abolir. Los movimientos de protesta juvenil anticapitalistas de 2012 _iniciados en la Puerta del Sol, luego en la Catedral de San Pablo londinense, y finalmente en el llamamiento a Ocupad Wall Street en América - fueron muy precisos en su identificación sociodiceica del mal: el capitalismo, sus banqueros, sus especuladores, sus parásitos.

La hipocresía democrática —-denunciada desde Tocqueville por pensadores de impecables ejecutorias liberales o progresistas - obliga hoy en día a no hacer explícita la sociodicea predominante entre los estamentos a veces más civilizados. Son tabúes, que se susurran en privado, o se callan. Ante el abrumador volumen de la pobreza en el mundo, no son pocos los que creen en lo que fuera un dogma de tiempos pasados, a saber, que la pobreza de los muchos es inevitable — siempre habrá pobres_ aunque no falten quienes, muy en privado, lleguen a confesar que, dentro de ciertos límites, es necesaria. Son abundantes los economistas que reconocen la necesidad de un modesto porcentaje de paro para que la economía vaya bien, aunque comprensiblemente sean parcos en expresarse sobre ello. Menos aún confesarán algunos que, para que haya justicia en el mundo, es necesaria una cierta cantidad de injusticia. (A este respecto, el coraje de Emile Durkheim al hacer hincapié en las funciones benéficas de ciertos niveles de anomía o delincuencia para la buena marcha de la sociedad merece una atención por lo menos similar a las afirmaciones de John Maynard Keynes sobre la necesidad de niveles modestos de paro.)

Mal entendida, como suele suceder, esta es una senda que nos conduciría a pensar, sociodiceicamente, que la completa desaparición de la delincuencia seria de lamentar, puesto que aboliría magistrados, alguaciles, vigilantes de prisiones, amén de vaciar instituciones tan respetadas por el pueblo hispano como la Guardia Civil.

Hay creencias sociodiceicas que se ocultan menos. Así acaece con el debilitamiento de la política social y el desprestigio de lo público, incrementados por una recesión económica que ha reducido la recaudación del Tesoro, que ha dado alas al liberalismo privatizador y al elogio a los cuatro vientos de los mercados como si éstos no sufrieran de las disfunciones que monopolios, oligopolios y controles conspirativos imponen). Suele suceder que una doctrina victoriosa busca concomitancias y simetrías que la refuercen, donde las haya. Esa es la razón por la que se ha extendido un darwinismo social vulgar - del cual Charles Darwin es tan inocente como Karl Marx lo es del marxismo- que 
fomenta y, sobre todo, justifica, puesto que de sociodicea hablamos, el entendimiento de la vida económica, política y cultural en sus propios términos. Confundiendo la capacidad de iniciativa individual, la disposición de cada ciudadano para elaborar su propia vida y buscarle algo de sentido, con una ideología que ignora aquellas desigualdades de raíz que impiden a la mayoría entrar en esa liza en condiciones de igualdad, la nueva ideología falsea la más elemental realidad para conveniencia de sus triunfadores y desdicha de sus víctimas, muchas de ellas salidas de sus propias filas.

\section{V}

La justificación de la imperfección del mundo, incluidos los desafueros e injusticias que ello entrañe, no excluye, por fortuna, la mejora cautelosa ni el reformismo. Por lo que sabemos de la historia humana, lo que sí queda de toda sociodicea es el uso frontal de la fuerza y la violencia para acabar con tal imperfección. La acumulación de pruebas fehacientes de que ello es así es abrumadora.

Tengo para mí que ello es válido tanto para el nivel micro como para el macrosociológico ${ }^{18}$ pero para mayor claridad me atendré a éste último. Con monótona repetición la ideología del 'daño necesario' extremo se ha impuesto en cuantos movimientos políticos han querido acabar de una vez por todas con una situación manifiestamente horrenda. Las proporciones de esta verdad son tales, que produce perplejidad comprobar la tozudez con que gentes responsables la ignoran. Huelga ilustrarlo, pero para no tener que repasar, aludiéndolos, a las hecatombes generadas a lo largo de toda la historia por semejante actitud, que podría haber culminado con los respectivos terrores que asociamos con los nombres de Hitler y Stalin, baste recordar, pues parece que fue ayer, que el régimen de los Khmer Rouge, encabezado por el tirano Pol Pot, en Cambodia, quiso corregir los males que asolaban al país asesinando y torturando a entre uno y tres millones de seres humanos (las cifras son imprecisas, pero ciertas) en un país con un población de 8 millones de personas, durante los años de 1975 a 1979, y ello según una ideología explícita (con su correspondiente sociodicea, por ende) amén de desplazamientos masivos de población realizados por medio de las bayonetas de la soldadesca al servicio del enloquecido partido único. Y, naturalmente, la indiferencia internacional, comenzando por la potencia colonialista, Francia, de quien en su estancia parisina aprendió todo Pol Pot.

No deberían pasársenos por alto aspectos en apariencia menos truculentos de los desmanes que ejercen los perfeccionistas a ultranza, es decir, los que quieren abolir una sociodicea (que, recordémoslo, puede o debe ser reformista) como parte de su ideolo-

${ }^{18} \mathrm{Cf}$. la obra de R. Collins para este aspecto de la relación entre los niveles micro y macro de la sociedad. También S. Giner (1997). 
gía. El perfeccionismo genera siempre imperfección. Así, el 'darwinismo social' (entendido como ideología que justifica el triunfo de los más inteligentes, listos, o ladinos, y no como lo que en puridad significa), la aceptación resignada de la pobreza masiva, la indiferencia ante las amenazas demográficas o ambientales que planean sobre la humanidad, debería ser parte de un análisis sociodiceico de nuestra realidad.

La vieja pero sólida tradición filosófica y sociológica que se forjó en el estudio de la ideología - desde Francis Bacon hasta Karl Mannheim, y después- debería ser revisitada y sobre todo enriquecida con una consideración rigurosa y sistemática de lo que significa la sociodicea para la cultura humana. La tarea no es menor. Y es, además, necesaria.

\section{RefERENCIAS BibLIOGRÁfICAS}

Bell, D. 1966. "Sociodicy: A Guide to Modern Usage." The American Scholar 35: 696-714.

Bourdieu, P. 1989. La noblesse d'État.París: Éditions de Minuit.

Bourdieu, P. 2003. Méditations pascaliennes. Londres: European Schoolbooks Limited.

Eisler, R. 1989. Kant Lexikon. Zúrich: Georg Olms Verlag.

Ferrarotti, F. 1972. Una sociologia alternativa. Dalla sociologia come tecnica del confomismo alla sociologia critica. Bari: De Donato.

Garzón Valdés, E. 2004. Calamidades. Barcelona: Gedisa.

Giner, S. 1997. "Intenciones humanas y estructuras sociales: para una lógica situacional." Pp. 11-26 en M. Cruz, coord. Acción Humana. Barcelona: Ariel.

Giner, S. 2004. Teoría sociológica clásica. Barcelona: Ariel.

Giner, S. 2011. El futuro del capitalismo. Barcelona: Península.

Giner, S. 2012. El origen de la moral. Barcelona: Península.

Giner, S. y Tábara, D. 1988. "Piedad cósmica y racionalidad ecológica." Revista Internacional de Sociología 19-20: 41-67.

Gouldner, A. 1971. The Coming Crisis of Western Sociology. Londres: Heinemann.

Gouldner, A. 1973. For Sociology. Londres: Allen Lane.

Martins, H. 2011. Experimentum Humanum: Civilizaçâo tecnológica e condiçâo humana. Lisboa: Relógio d'Água, 2011.

Parsons, T. 1970. "Equality and Inequality in Modern Society, or Social Stratification Revisited." Sociological Inquiry 40: 13-72.

Parsons, T. 1949. The Structure of Social Action. Glencoe, III.: The Free Press. 
Pérez Hernáiz, H. A. 2011. "Competing Explanations of Global Evils: Theodicy, Social Sciences and Conspiracy Theories". Journal of Area Based Global Trends, AGLOS, 2: 22-45.

Rodríguez Ibáñez, J. E. 1978. Teoría crítica y sociología. Madrid: Siglo XXI.

Sen, A. 2009. The Idea of Justice. Londres: Penguin.

Sgalambro, M. 1993. Diario teológico. Milán: Adelphi Edizioni.

Sgalambro, M. 2004. De mundo pessimo. Milán: 2004.

Shils, E. 1956. The Torment of Secrecy. Nueva York: The Free Press.

Wilkinson, R. y Picket, K. 2010. The Spirit Level. Londres: Penguin.

Salvador Giner es Catedrático Emérito de la Universidad de Barcelona y Presidente del Institut d'Estudis Catalans, Academia de las Ciencias y Humanidades de Barcelona.

RECIBIDO: $12 / 09 / 2013$

ACEPTADO: 21/02/2014

Publicado on-line: 9/04/2014 